\title{
Overexpression of Cell Cycle Proteins of Peripheral Lymphocytes in Patients with Alzheimer's Disease
}

\author{
Hyeran Kim¹, Young-Ah Kwon², Inn Sook Ahn², Sangha Kim¹, \\ Seonwoo Kim ${ }^{3}$, Sangmee Ahn $\mathrm{Jo}^{4}$, and Doh Kwan $\mathrm{Kim}^{1,2 \bowtie}$ \\ ${ }^{1}$ Department of Psychiatry, Samsung Medical Center, Sungkyunkwan University School of Medicine, Seoul, Republic of Korea \\ ${ }^{2}$ Center for Clinical Research, Samsung Biomedical Research Institute, Seoul, Republic of Korea \\ ${ }^{3}$ Biostatistics Unit, Samsung Biomedical Research Institute, Seoul, Republic of Korea \\ ${ }^{4}$ Department of Pharmacy, College of Pharmacy, Dankook University, Cheonan, Republic of Korea
}

Objective Biological markers for Alzheimer's disease (AD) will help clinicians make objective diagnoses early during the course of dementia. Previous studies have suggested that cell cycle dysregulation begins earlier than the onset of clinical manifestations in AD.

Methods We examined the lymphocyte expression of cell cycle proteins in AD patients, dementia controls (DC), and normal controls (NC). One-hundred seventeen subjects (36 AD, $31 \mathrm{DC}$, and $50 \mathrm{NC}$ ) were recruited. The cell cycle proteins CDK2, CDK4, CDK6, cyclin $\mathrm{B}$, and cyclin $\mathrm{D}$ were measured in peripheral lymphocytes. Cell cycle protein expression in the three groups was compared after adjusting for age and sex.

Results The levels of cell cycle proteins CDK2, CDK4, CDK6, cyclin B, and cyclin D were significantly higher in AD patients than in the NC subjects. The DC group manifested intermediate levels of cell cycle proteins compared with the AD patients and the NC subjects. The present study indicates that cell cycle proteins are upregulated in the peripheral lymphocytes of AD patients.

Conclusion Cell cycle dysregulation in peripheral lymphocytes may present a promising starting point for identifying peripheral biomarkers of $\mathrm{AD}$.

Psychiatry Investig 2016;13(1):127-134

Key Words Biomarker, Cell cycle proteins, Alzheimer's disease, Cyclin, Cyclin-dependent kinase, Peripheral lymphocyte.

\section{INTRODUCTION}

Early recognition of Alzheimer's disease $(\mathrm{AD})$ is important for a variety of clinical reasons, especially with respect to initiating early treatment before neuronal loss occurs. However, it is difficult for clinicians to identify $\mathrm{AD}$ early in the course of dementia. Therefore, clinicians expect that the identification of biological markers associated with $\mathrm{AD}$ will allow them to make more objective early diagnoses.

A failure of regulation of the cell cycle has been proposed as a mechanism of neuronal apoptosis in $\mathrm{AD} \cdot{ }^{1-6}$ Normally, differentiated neurons do not divide. However, it has been found

Received: January 5, 2015 Revised: May 19, 2015

Accepted: June 13, 2015 Available online: November 20, 2015

$\triangle$ Correspondence: Doh Kwan Kim, MD, PhD

Department of Psychiatry, Samsung Medical Center, Sungkyunkwan University School of Medicine, 81 Irwon-ro, Gangnam-gu, Seoul 06351, Republic of Korea Tel: +82-2-3410-3582, Fax: +82-2-3410-0941, E-mail: paulkim@skku.edu

(a) This is an Open Access article distributed under the terms of the Creative Commons Attribution Non-Commercial License (http://creativecommons.org/licenses/by$\mathrm{nc} / 3.0$ ) which permits unrestricted non-commercial use, distribution, and reproduction in any medium, provided the original work is properly cited. that cell cycle components are present and actual DNA replication occurs in at-risk neurons in the $\mathrm{AD}$ brain. ${ }^{6-8}$ Cell cycle proteins that stimulate cell cycle progression to mitosis have been reported to be elevated in the $\mathrm{AD}$ brain. ${ }^{1,5,7,9}$ If cell cycle re-entry is forced in terminally differentiated neurons, the neurons die rather than divide. ${ }^{1,3}$ Thus, cell cycle dysregulation in differentiated neurons has been suggested as a feature of the pathogenesis of $\mathrm{AD}{ }^{2,4-6}$ Moreover, this process begins earlier than the onset of clinical manifestations in $\mathrm{AD}^{6,10}$

One of the prominent features of $\mathrm{AD}$ is neuronal loss in the central nervous system (CNS), but the pathologic processes in the CNS are difficult to assess in living subjects. Evidence indicates that molecular changes in the level of oxidative stress and mitochondrial function are observed in peripheral cells such as lymphocytes as well as in neurons of AD. ${ }^{11-13}$ Moreover, accumulating evidence of cell cycle dysregulations has been found in peripheral lymphocytes of $\mathrm{AD} .^{10,14}$ Thus, we sought to determine whether cell cycle dysregulation, besides that involved in neuronal death within the CNS, could also occur in the lymphocytes from peripheral blood of the patients with 
$\mathrm{AD}$. To this end, we already carried out a study in $\mathrm{AD}$ patients and normal controls focusing on the assessment of the viability and proliferation activity of peripheral lymphocytes following mitotic stimulation. ${ }^{15}$ The results showed that peripheral lymphocytes from $\mathrm{AD}$ patients are more vulnerable to cell death than those from normal controls, and that their cell cycle progression is advanced.

Hence, based on these earlier findings, we examined the expressions of cell cycle proteins in peripheral lymphocytes, and of cyclin-dependent kinases (CDKs) and cyclins, in this study. We compared the cell cycle protein expressions of lymphocytes in $\mathrm{AD}$ patients, dementia controls (DC), and normal controls (NC) to clarify whether cell cycle protein overexpression is specific for $\mathrm{AD}$. In addition, in order to identify whether cell cycle protein expression is associated with disease severity, we investigated the relationship between cell cycle protein expression and indices of disease severity in $\mathrm{AD}$ patients.

\section{METHODS}

\section{Subjects}

Dementia patients diagnosed using the Diagnostic and Statistical Manual of Mental Disorders-Fourth Edition (DSM-IV) criteria were recruited at the Geropsychiatry Clinic of a university hospital (Figure 1). All patients underwent routine laboratory tests, neurologic examination, neuroimaging (MRI), and neuropsychological evaluation. Dementia patients were classified into two groups: $\mathrm{AD}$ and non- $\mathrm{AD}$ dementia groups (Figure 1). AD was diagnosed using DSM-IV and NINCDS-ADRDA (National Institute of Neurological and Communicative Disorders and Stroke-Alzheimer's Disease and Related Disorders Association) criteria. From the non-AD dementia group, only the patients with subcortical vascular dementia (SVaD) were enrolled as DCs (Figure 1). SVaD patients met the criteria for vascular dementia described by the DSM-IV and also fulfilled the imaging criteria for SVaD proposed by Erkinjuntti and his colleagues. ${ }^{16}$ These patients showed at least two focal neurological signs that included corticobulbar signs (facial palsy, dysarthria, dysphagia, or pathologic laughing or crying), pyramidal signs (hemiparesis, hyperactive deep tendon reflexes, or extensor plantar responses), or parkinsonism (shortstep gait, festination, shuffling gait, decreased arm swing while walking, rigidity, bradykinesia, or postural instability). Patients over age 90 or with other significant medical, neurologic, or psychiatric illnesses including major depressive disorder were excluded. Finally, $36 \mathrm{AD}$ patients and $31 \mathrm{DC}$ patients were included in the analysis (Figure 1).

The NCs consisted of elderly volunteers who responded to advertisements (Figure 1). NC subjects underwent neurologic examination and neuropsychological evaluation. All subjects in this group scored 26 points or higher on the Korean version of the Mini Mental State Examination (K-MMSE), and had no

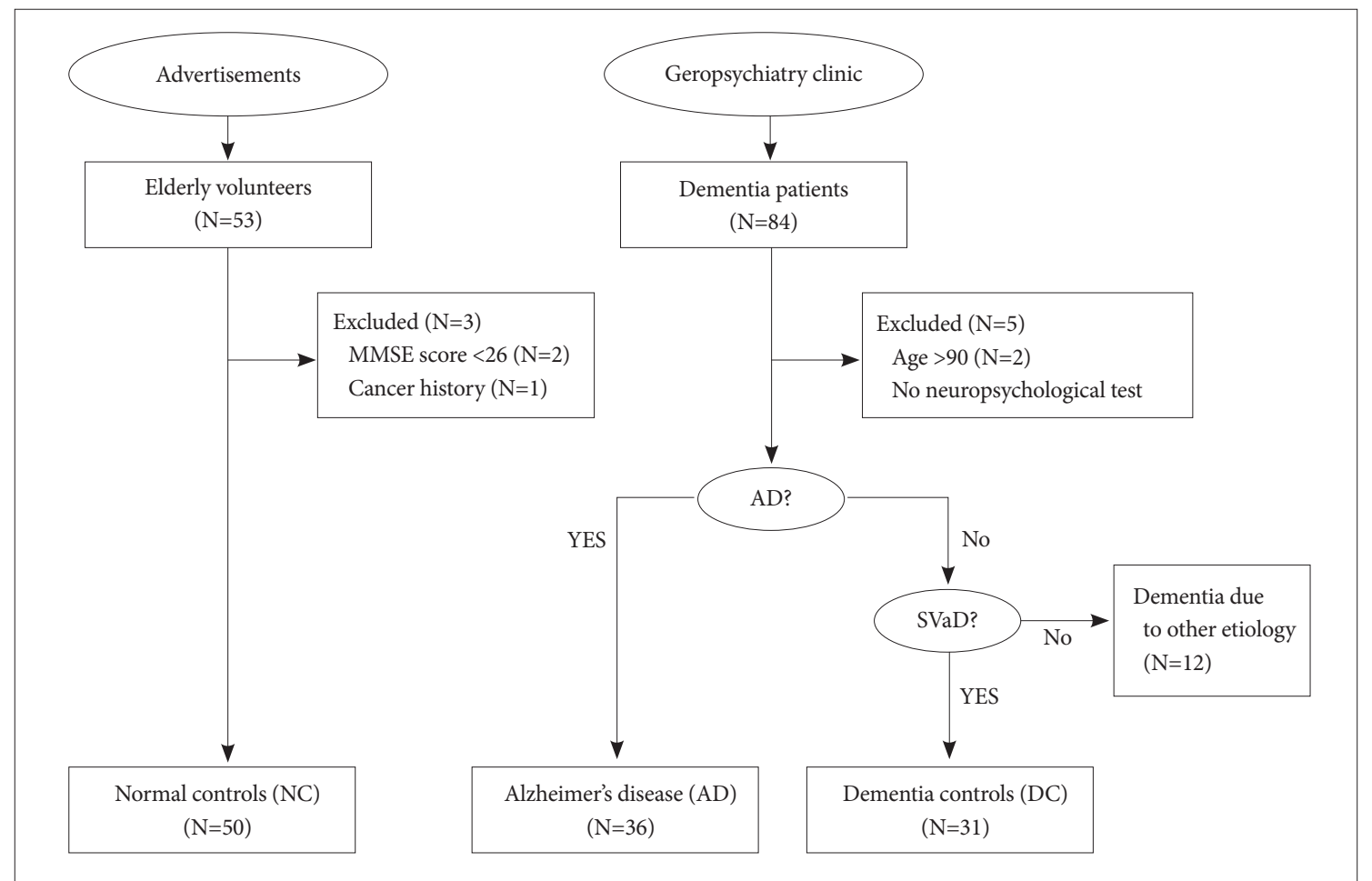

Figure 1. Flow of subjects through the study. AD: Alzheimer's disease, SVaD: subcortical vascular dementia, MMSE: Mini Mental State Examination. 
evidence of medical, neurologic or psychiatric disorder.

No study subject was suffering from inflammatory, infectious, or neoplastic disease, or was taking drugs capable of interfering with white blood cells. The study protocol was approved by the Institutional Review Board of Samsung Medical Center. After complete description of the study, written informed consent was obtained.

\section{Evaluation of disease severity}

The K-MMSE, Clinical Dementia Rating (CDR), Seoul Activity of Daily Living (S-ADL), and Seoul Instrumental Activity of Daily Living (S-IADL) were administered for dementia patients. ${ }^{17-19}$ The S-ADL and S-IADL were developed to assess activities of daily living (ADL) and instrumental activities of daily living (IADL), respectively. S-ADL items include things such as using the toilet, maintaining personal hygiene, bathing, and dressing, and S-IADL items include things such as doing household chores, using transportation, managing finances, and keeping appointments. The S-ADL is composed of 12 items with scores from 0 (normal) to 2 (impaired), and the S-IADL is composed of 15 items with scores from 0 (normal) to 3 (impaired). Total scores range $0-24$ for the S-ADL and $0-45$ for the SIADL. Cronbach's alpha is $0.94{ }^{18}$ The S-ADL and S-IADL were assessed through interview with the main caregiver, defined as 'the person living together with the patient' or 'the person spending some regular time with the patient every day in case of not living together'.

Normal control subjects underwent K-MMSE, Beck Depression Inventory (BDI), and the short form of the Minnesota Multiphasic Personality Inventory (MMPI) ${ }^{20,21}$ to screen out those with significant cognitive impairment, depressive symptoms, and psychopathology. Neuropsychological tests and interviews were performed by a MA-level psychologist and supervised by a $\mathrm{PhD}$-level psychologist.

\section{Cell preparation \& protein analysis}

A total of $20 \mathrm{~mL}$ of peripheral venous blood was obtained from all study subjects. Blood was stored at $4^{\circ} \mathrm{C}$ immediately after venipuncture and assayed within 24 hours. Mononuclear cells were isolated by centrifugation ( $300 \mathrm{~g}$ for 15 minutes, Ficoll-Hypaque, Pharmacia, Duebendorf, Switzerland) and washed twice with PBS (phosphate buffered saline, Sigma, Switzerland). Lymphocytes were separated using Hank's balanced salt solution (Sigma, Switzerland).

Cellular lysates were prepared by suspending no more than $10^{7}$ cells $/ \mathrm{mL}$ in $100 \mu \mathrm{L}$ of lysis buffer [50 mM Hepes ( $\mathrm{pH}$ 7.5), $150 \mathrm{mM} \mathrm{NaCl}, 1 \mathrm{mM}$ EDTA, $1 \mathrm{mM} \mathrm{NaF}$, and 0.1\% Tween 20] containing $0.1 \mathrm{mM}$ PMSF, $1 \mathrm{mM}$ leupeptin, and $20 \mu \mathrm{g} / \mathrm{mL}$ aprotinin (all protease inhibitors were from Sigma, Switzerland). Cells were disrupted by sonication and extracted in ice for $30 \mathrm{~min}$. The amount of protein contained in the lysates was determined using Bio-Rad protein assay kits (Bio-Rad Laboratories, CA).

To detect CDK2, CDK4, CDK6, Cyclin B, and Cyclin D, lysates $(100 \mu \mathrm{g})$ were denatured by boiling in sample buffer and separated on $12 \%$ SDS-polyacrylamide gels. Separated proteins were electrotransferred to Immobilon-P membranes (Millipore, Volkestwil, Switzerland), which were then blocked with a 5\% solution of nonfat milk in PBS containing 0.5\% Tween 20 and probed for 1 hour with polyclonal rabbit antibodies to CDK2, CDK4, CDK6, Cyclin B, and Cyclin D (Santa Cruz Biotechnology, CA). Horseradish peroxidase-conjugated anti-rabbit IgG (Pierce Biotechnology Inc.) was used as a secondary antibody, and membranes were developed using SuperSignal ${ }^{\mathbb{}}$ West Femto maximum sensitivity substrate kit (Pierce Biotechnology Inc.). Relative band optical densities were measured using a computer-assisted image analyzer (Image Lab 2.2.4, MCM Design Inc.). Numerical values for sample signals are presented in arbitrary units $(\mathrm{AU}){ }^{22}$

\section{Statistical analysis}

Continuous variables were presented as medians [interquartile range], and categorial variables were presented by frequency and proportion. Overall comparisons of the demographic data and cell cycle proteins among the $\mathrm{AD}, \mathrm{DC}$, and $\mathrm{NC}$ groups were made using the Kruskal-Wallis test due to non-normality and the Chi-square test. The clinical characteristics of the $\mathrm{AD}$ and DC groups were compared using the Mann-Whitney U test. Pairwise comparisons of the cell cycle proteins in the $\mathrm{AD}$,

Table 1. Demographic and clinical characteristics of subjects

\begin{tabular}{|c|c|c|c|c|}
\hline & \multicolumn{2}{|c|}{ Dementia } & \multirow{2}{*}{ Normal control $(\mathrm{N}=50)$} & \multirow{2}{*}{$\mathrm{p}$} \\
\hline & $\mathrm{AD}(\mathrm{N}=36)$ & $\mathrm{DC}(\mathrm{N}=31)$ & & \\
\hline $\operatorname{Sex}(M / F)^{*}$ & $12 / 24$ & $8 / 23$ & $11 / 39$ & 0.50 \\
\hline Age $(y r)^{\dagger}$ & $73.0[67.5,77.5]$ & $72.0[65.0,78.0]$ & $69.5[61.0,74.0]$ & 0.09 \\
\hline Education $(\mathrm{yr})^{\dagger}$ & $9.0[6.0,16.0]$ & $6.0[6.0,12.0]$ & $7.0[6.0,12.0]$ & 0.45 \\
\hline Disease duration $(\mathrm{mo})^{\ddagger}$ & $38.0[15.0,56.0]$ & $24.0[18.5,48.0]$ & & 0.55 \\
\hline $\mathrm{K}_{-\mathrm{MMSE}^{\dagger}}$ & $16.5[11.5,20.5]$ & $18[16,20]$ & $28.0[27.0,28.0]$ & $<0.01$ \\
\hline
\end{tabular}

${ }^{*}$ chi-square test, ${ }^{\dagger}$ median [interquartile range], Kruskal-Wallis test, ${ }^{\ddagger}$ median [interquartile range], Mann-Whitney U test between AD and DC. AD: Alzheimer's disease, DC: dementia controls, K-MMSE: Korean version of Mini-Mental Status Examination 
DC, and NC groups were made with Tukey's test using ranks. Furthermore, cell cycle proteins in early, and advanced $\mathrm{AD}$ were compared with the NCs using Dunnett's test using ranks.

Correlations between study variables were investigated using Spearman's correlation analysis. AUC [Area under the ROC (Receiver Operating Curve)], sensitivity, specificity, Positive Predictive Value (PPV), and Negative Predictive Value (NPV) of CDKs and cyclins were calculated to examine their possibilities as biomarkers for AD diagnosis. Statistical analyses were performed using SAS software (SAS Institute Inc, Cary, NC), and $\mathrm{p}<0.05$ was considered significant.

\section{RESULTS}

\section{Subject characteristics}

The clinical characteristics and demographic data of the $\mathrm{AD}$, DC, and NC groups are presented in Table 1. No significant differences were found among the three groups in terms of age, sex, or education. However, non-significant age and sex differences were found; the $\mathrm{AD}$ group was older and had more male patients than the DC or NC group (Table 1). Because of previous studies that suggested associations between cell cycle proteins and age or sex, we adjusted for age and sex when we compared cell cycle protein expression in the three groups.

Dementia in the study patients ranged from mild to severe, with median scores on the K-MMSE ${ }^{17}$ of 16.5 and 18.0 for $\mathrm{AD}$ and $\mathrm{DC}$ patients, respectively. The $\mathrm{AD}$ and $\mathrm{DC}$ groups were similar with respect to disease duration and MMSE scores (Table 1).

\section{Cell cycle protein expression in AD, DC, and NC groups}

The cell cycle protein expression in the three study groups is presented in Table 2. All cell cycle proteins (CDK2, CDK4, CDK6, cyclin B, and cyclin D) were significantly higher in the $\mathrm{AD}$ patients than in the NCs, after controlling for age and sex $(\mathrm{p}<0.005)$ (Table 2). The DC group had intermediate levels of cell cycle proteins compared with those in the $\mathrm{AD}$ and $\mathrm{NC}$ groups. AD-DC group comparisons revealed that $\mathrm{AD}$ patients had significantly higher levels of CDK2 and
CDK6 ( $<0.0001$ for CDK2 and CDK6) (Table 2) and nonsignificantly higher levels of CDK4 (median 217.31 vs. 201.81, $\mathrm{AD}$ vs. DC) (Table 2).

\section{Cell cycle proteins and disease severity in AD}

Alzheimer patients were dichotomized into early stage $\mathrm{AD}$ (CDR scores of 0.5 or 1 ) and advanced stage $\mathrm{AD}$ (CDR scores of 2 or 3 ), and cell cycle protein expression was compared among the $\mathrm{NC}$, early stage $\mathrm{AD}$, and advanced stage $\mathrm{AD}$ groups (Figure 2, Table 3). Cell cycle protein expression in lymphocytes was increased in the early stage $\mathrm{AD}$ patients compared with the NCs ( $<<0.0005$ for CDK2, CDK4, CDK6, and cyclin $\mathrm{B}, \mathrm{p}=0.17$ for cyclin D) (Figure 2, Table 3). Cell cycle proteins were over-expressed beginning in the early stage of $\mathrm{AD}$. Comparing the early and advanced stage $\mathrm{AD}$ groups, the expression levels of CDKs and cyclin B did not differ, but cyclin D levels were higher in the advanced stage than in the early stage $(\mathrm{p}=$ 0.16 for CDK2, $\mathrm{p}=0.38$ for $\mathrm{CDK} 4, \mathrm{p}=0.90$ for $\mathrm{CDK} 6, \mathrm{p}=0.30$ for cyclin B, $\mathrm{p}=0.02$ for cyclin D) (Figure 2).

Correlation analysis was conducted between cell cycle protein expression and indices of disease severity in the $\mathrm{AD} \mathrm{pa-}$ tients. CDKs were not related to the outcomes of neuropsychological examination. Unlike CDKs, there were significant correlations between cyclin levels and impaired neuropsychological outcomes. Cyclin D levels in lymphocytes were found to be significantly correlated with K-MMSE and S-IADL scores $(\rho=-0.43, p=0.009$ for K-MMSE; $\rho=0.47, p=0.004$ for $S$ IADL). A relationship was also found between cyclin B levels and S-IADL scores $(\rho=0.34, p=0.04)$.

\section{Correlations of cell cycle proteins}

The expression levels of CDKs were found to correlate with one another $(\rho=0.38, p<0.001$ for CDK2 and CDK4; $\rho=0.43$, $\mathrm{p}<0.001$ for CDK4 and CDK6; $\rho=0.35, \mathrm{p}<0.001$ for CDK2 and CDK6), as were the cyclins ( $\rho=0.26, p=0.005$ for cyclin $B$ and cyclin D). In terms of correlations between cyclins and CDKs, cyclin B was significantly correlated with CDKs $(\rho=0.33$, $p<$ 0.001 for CDK2; $\rho=0.25, p=0.006$ for CDK4; $\rho=0.30, p=0.001$ for CDK6), and cyclin D was significantly correlated with $\operatorname{CDK} 2(\rho=0.33, p<0.001)$.

Table 2. Cell cycle proteins in $A D$, dementia controls, and normal controls

\begin{tabular}{lccccccc}
\hline & $\mathrm{AD}$ & $\mathrm{DC}$ & $\mathrm{NC}$ & \multicolumn{3}{c}{ Overall } & \multicolumn{3}{c}{ AD vs. DC AD vs. NC DC vs. NC } \\
\hline $\mathrm{CDK} 2\left(\times 10^{3} \mathrm{AU}\right)$ & $235.16[205.19,246.80]$ & $196.52[190.20,211.23]$ & $189.16[178.20,210.62]$ & $<0.0001$ & $<0.0001$ & $<0.0001$ & 0.1425 \\
$\mathrm{CDK} 4\left(\times 10^{3} \mathrm{AU}\right)$ & $217.31[200.18,242.49]$ & $201.81[188.18,225.63]$ & $189.21[178.20,211.33]$ & $<0.0001$ & 0.0854 & $<0.0001$ & 0.0367 \\
$\mathrm{CDK} 6\left(\times 10^{3} \mathrm{AU}\right)$ & $225.63[210.32,238.30]$ & $192.26[182.36,200.14]$ & $189.20[178.20,215.84]$ & $<0.0001$ & $<0.0001$ & $<0.0001$ & 0.6831 \\
Cyclin B $(\mathrm{AU})$ & $84.62[72.84,95.57]$ & $80.26[69.84,87.26]$ & $66.29[59.65,74.65]$ & $<0.0001$ & 0.4581 & $<0.0001$ & $<0.0001$ \\
Cyclin D $(\mathrm{AU})$ & $137.19[120.45,171.72]$ & $120.36[112.56,130.46]$ & $115.55[109.42,132.56]$ & 0.0031 & 0.1076 & 0.0016 & 0.4514 \\
\hline
\end{tabular}

Values are median [interquartile range]. Kruskal-Wallis test and Tukey's method using ranks for multiple comparisons. AD: Alzheimer's disease, DC: dementia controls, NC: normal controls, CDK: cyclin-dependent kinase, AU: arbitrary unit 


\section{Diagnostic performance of cell cycle proteins as a marker of AD}

The sensitivity, specificity, and diagnostic accuracy associated with each cut-off concentration of cell cycle proteins were computed, and from these results ROC curves were derived. AUCs of CDK2 were 0.835 (95\% CI: 0.751, 0.919). Twenty three of the $36 \mathrm{AD}$ patients (63.9\%) and 75 of the 81 non- $\mathrm{AD}$ patients and NC (92.6\%) had CDK2 levels higher than $221.18\left(\times 10^{3} \mathrm{AU}\right)$. This cut-off resulted in PPV of 0.793 $(=23 / 29$; $95 \%$ CI: $0.646,0.940)$ and NPV of $0.852(=75 / 88$, 95\% CI: 0.778, 0.926).

\section{DISCUSSION}

The present study demonstrates that the lymphocyte expression levels of cell cycle proteins are upregulated in $\mathrm{AD}$ patients, even in the early stage. This result is consistent with previous reports that cell cycle re-entry mediates neuronal cell death in $A D .^{1-6}$ The majority of neurons in the normal adult brain are in the resting (G0) phase, wherein they are differentiated but do not proliferate. They are commonly viewed as being too mature to successfully complete the cell cycle. However, in AD, some neurons may be stimulated to reenter the G1 phase from the G0 phase, and this leads to cell death. ${ }^{2}$ Cell cycle proteins, such as cyclins and CDKs are responsible for progression through the cell cycle. ${ }^{1723}$
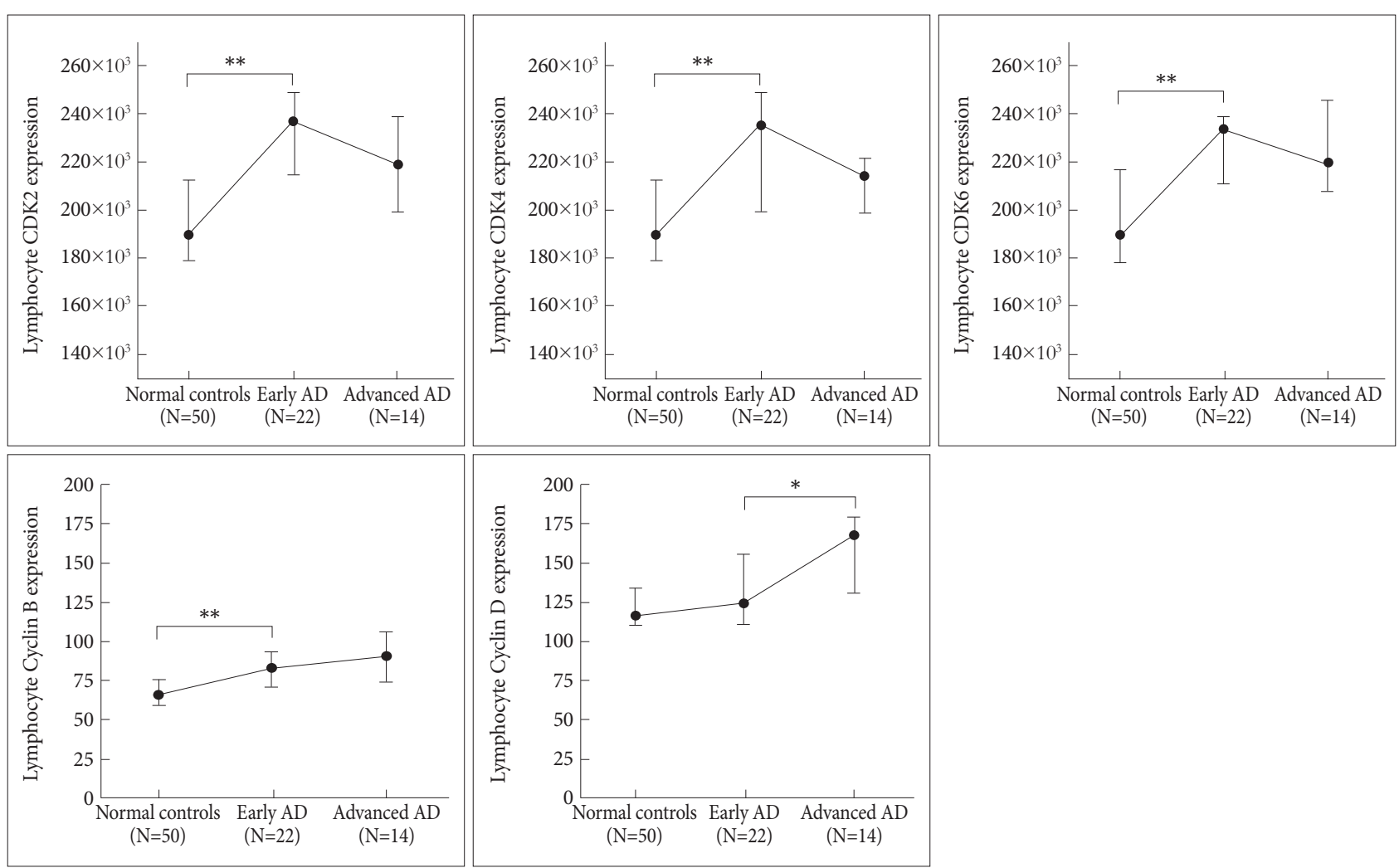

Figure 2. Cell cycle proteins in NCs and early stage and advanced stage AD patients. Circles and bars represent medians and interquartile ranges (25\%ile and $75 \%$ ile). ${ }^{*} p<0.05,{ }^{* *} p<0.001$. AD: Alzheimer's disease, CDK: cyclin-dependent kinase.

Table 3. Cell cycle proteins in early AD, advanced AD, and normal controls

\begin{tabular}{lccccc}
\hline & eAD & aAD & NC & eAD vs. NC & aAD vs. NC \\
\hline CDK2 $\left(\times 10^{3} \mathrm{AU}\right)$ & $236.8[215.81,246.87]$ & $218.7[200.16,235.8]$ & $189.16[178.20,210.62]$ & $<0.0001$ & 0.0002 \\
CDK4 $\left(\times 10^{3} \mathrm{AU}\right)$ & $235.46[200.18,246.8]$ & $214.35[200.18,219.95]$ & $189.21[178.20,211.33]$ & $<0.0001$ & 0.0073 \\
CDK6 $\left(\times 10^{3} \mathrm{AU}\right)$ & $233.03[214.2,236.88]$ & $219.5[210.2,244.62]$ & $189.20[178.20,215.84]$ & 0.0001 & 0.0015 \\
Cyclin B (AU) & $82.4[70.27,92.65]$ & $90.65[75.42,105.23]$ & $66.29[59.65,74.65]$ & 0.0001 & $<0.0001$ \\
Cyclin D $(\mathrm{AU})$ & $123.48[109.26,152.96]$ & $166.79[129.45,178.06]$ & $115.55[109.42,132.56]$ & 0.1682 & 0.0002 \\
\hline
\end{tabular}

Values are median [interquartile range]. Dunnett's test using ranks for multiple comparisons with NC. AD: Alzheimer's disease, NC: normal controls, eAD: early Alzheimer's disease, aAD: advanced Alzheimer's disease, CDK: cyclin-dependent kinase, AU: arbitrary unit 
Exit from the G0 phase is primarily under the control of cyclin D in association with CDK4 or CDK6; cyclin E and CDK2 are essential for entry into the $\mathrm{S}$ phase, and cyclin $\mathrm{B}$ and CDK1 promote entry into the $\mathrm{M}$ phase, the mitotic phase. ${ }^{23,24}$ Cyclins and CDKs are tightly regulated by extra- or intra-cellular signals, and the uncontrolled regulation of cell cycle proteins is related to pathologic conditions. ${ }^{25}$ The increased expression of cell cycle proteins has been reported in the AD brain, especially in neurons that contain neurofibrillary tangles and near amyloid plaques. ${ }^{2,3,5,9}$ Moreover, inappropriately induced cell cycle proteins in differentiated neurons can lead to tau phosphorylation and pathologic changes similar to those observed in the $\mathrm{AD}$ brain. ${ }^{2,5,8,26}$

Previous studies indicate that cell cycle dysregulation appears early in the brain, before the onset of fully developed AD. ${ }^{6,10}$ In this study, we found that cell cycle proteins except for cyclin $\mathrm{D}$, were over-expressed beginning in the early stages of $\mathrm{AD}$ (Figure 2, Table 3). Advanced stage $\mathrm{AD}$ patients did not show additional increases in the lymphocyte expression of CDKs and cyclin B, but cyclin D levels were significantly higher in advanced $\mathrm{AD}$ patients than in early $\mathrm{AD}$ patients. When we attempted to correlate cell cycle protein expression with indices of disease severity in $\mathrm{AD}$ patients, $\mathrm{CDK}$ expression did not correlate with any disease severity indices but, cyclins, especially cyclin $\mathrm{D}$, did. These findings suggest that lymphocyte CDK expression tends to remain high from the early stages of $\mathrm{AD}$, whereas cyclin expression tends to be higher with more advanced illness. The reasons for this are at present unclear but may be related to the different characteristics of CDKs and cyclins. CDKs are well-conserved protein kinases, but cyclin proteins are less conserved than CDKs. ${ }^{27,28}$ Whereas levels of CDKs remain constant, expression of cyclins varies following periodic transcriptional or post-transcriptional regulation. ${ }^{25}$ Thus, it could be speculated that cyclins are better for indicating state-dependent changes in $\mathrm{AD}$ than are CDKs.

In the present study, cell cycle protein levels were measured in peripheral lymphocytes and were elevated in $\mathrm{AD}$ patients compared with NCs. Studies have shown similarities between the neurons and lymphocytes in receptor expression and intracellular transduction processes. ${ }^{29}$ Accumulating evidence indicates that lymphocytes may be used as a peripheral probe in $\mathrm{AD} .{ }^{11,12,30} \mathrm{AD}$ studies have demonstrated the existence of various biological disturbances, such as enhanced oxidative stress, ${ }^{31,32}$ elevated intracellular calcium, ${ }^{33}$ alteration of mitochondrial function, increased caspase activation, ${ }^{34}$ and apoptosis triggered by beta-amyloid peptide ${ }^{35}$ in human and animal lymphocytes, which suggests that neurons and lymphocytes share some part of the cell death mechanism in $\mathrm{AD}$. Cell cycle abnormalities have also been found in peripheral lymphocytes in $\mathrm{AD} .{ }^{10} \mathrm{AD}$ lymphocytes have shown abnormal proliferation after stimu- lation with UVB or Epstein-Barr virus, ${ }^{14,36-38}$ and a few studies have investigated cell cycle proteins and cell cycle protein-associated kinase activity in such lymphocytes. ${ }^{36,37}$ Although cell cycle protein-associated kinase activity was enhanced in $\mathrm{AD}$, the investigators failed to find differences in the expression levels of cell cycle proteins between $\mathrm{AD}$ patients and normal controls. ${ }^{36,37}$ The present study showed that cell cycle proteins were upregulated in the freshly isolated lymphocytes of $\mathrm{AD}$ patients. Differences in experimental settings may explain this discrepancy. In previous studies, lymphoblasts infected with Epstein-Barr virus were used, and thus, conditions may have been created that reduced differences between $\mathrm{AD}$ patients and NCs.

Some previous studies have shown that the involvement of cell cycle processes occurs in dementia other than AD-type and have furthermore suggested that cell cycle dysregulation is unlikely to be specific to $\mathrm{AD} .{ }^{39}$ Cell cycle protein immunoreactivities have been observed in brains with neurodegenerative disorders other than $\mathrm{AD}$, and vulnerable neurons have also been shown to exhibit increased expression of cell cycle proteins following ischemic insult. ${ }^{40,41}$ However, in the present study, the quantitative analysis comparing the $\mathrm{AD}$ and $\mathrm{DC}$ groups showed that cell cycle protein elevations in $\mathrm{AD}$ patients are more prominent than in the DCs. CDK4 and cyclin B differences between the $\mathrm{AD}$ and $\mathrm{DC}$ groups did not reach statistical significance, which may have been due to sample size limitations. In this study, the sample size of the DC group was smaller than that of the NC group, and the expressional differences of cell cycle proteins between the $\mathrm{AD}$ and $\mathrm{DC}$ groups were smaller than those between the $\mathrm{AD}$ and $\mathrm{NC}$ groups. Therefore, the sample size might not have been sufficiently large to achieve statistical significance when the differences between $\mathrm{AD}$ and $\mathrm{DC}$ patients were examined.

We have to admit that the severity of depression may influence the disease severity of dementia. However, our study reflects real conditions related to managing dementia in a clinical setting. We further compared the cell cycle protein expression levels in subjects with dementia due to other etiology with those in the DC group and found no significant differences in cell cycle protein expression among the three diagnostic subgroups: vascular dementia vs. Lewy body dementia plus Parkinson disease dementia vs. alcoholic dementia plus dementia due to head trauma ( $p=0.39$ for CDK2, $p=0.96$ for CDK4, $\mathrm{p}=0.18$ for CDK6, $\mathrm{p}=0.12$ for cyclin $\mathrm{B}$, and $\mathrm{p}=0.06$ for $\mathrm{cyclin} \mathrm{D}$, all by the Kruskal-Wallis test).

The third limitation of this study is that it has not yet been established whether the cell cycle protein overexpression observed in lymphocytes is associated with that observed in the brains and neurons of AD patients. Although an increase in the levels of cell cycle proteins was observed in the lympho- 
cytes of $\mathrm{AD}$ patients in the present study, few studies have been undertaken to elucidate the relationship between the lymphocyte and brain concentrations of cell cycle proteins. Additional studies are thus needed to determine association.

The present study indicates that cell cycle dysregulation is present in the peripheral lymphocytes of $\mathrm{AD}$ patients. Biochemical investigations based on brain biopsies in $\mathrm{AD}$ are unrealistic, and thus lymphocytes may serve as an easily accessible neural probe to investigate $\mathrm{AD}$ in living subjects. Moreover, cell cycle dysregulation in peripheral lymphocytes presents a promising starting point for indentifying peripheral biomarkers of $\mathrm{AD}$.

\section{Acknowledgments}

This study was supported by a grant of Korea Health Technology R\&D Project through the Korea Health Industry Development Institute, Ministry of Health \& Welfare, Republic of Korea (HI14C2071).

\section{REFERENCES}

1. Busser J, Geldmacher DS, Herrup K. Ectopic cell cycle proteins predict the sites of neuronal cell death in Alzheimer's disease brain. J Neurosci 1998;18:2801-2807.

2. McShea A, Lee HG, Petersen RB, Casadesus G, Vincent I, Linford NJ, et al. Neuronal cell cycle re-entry mediates Alzheimer disease-type changes. Biochim Biophys Acta 2007;1772:467-472.

3. Nuydens R, de Jong M, Van Den Kieboom G, Heers C, Dispersyn G, Cornelissen F, et al. Okadaic acid-induced apoptosis in neuronal cells: evidence for an abortive mitotic attempt. J Neurochem 1998;70:11241133.

4. Raina AK, Zhu X, Rottkamp CA, Monteiro M, Takeda A, Smith MA. Cyclin' toward dementia: cell cycle abnormalities and abortive oncogenesis in Alzheimer disease. J Neurosci Res 2000;61:128-133.

5. Vincent I, Jicha G, Rosado M, Dickson DW. Aberrant expression of mitotic cdc2/cyclin B1 kinase in degenerating neurons of Alzheimer's disease brain. J Neurosci 1997;17:3588-3598.

6. Yang Y, Mufson EJ, Herrup K. Neuronal cell death is preceded by cell cycle events at all stages of Alzheimer's disease. J Neurosci 2003;23:25572563.

7. Arendt T, Rodel L, Gartner U, Holzer M. Expression of the cyclin-dependent kinase inhibitor p16 in Alzheimer's disease. Neuroreport 1996; 7:3047-3049.

8. Kondratick CM, Vandre DD. Alzheimer's disease neurofibrillary tangles contain mitosis-specific phosphoepitopes. J Neurochem 1996;67: 2405-2416.

9. Hoozemans JJ, Bruckner MK, Rozemuller AJ, Veerhuis R, Eikelenboom P, Arendt T. Cyclin D1 and cyclin E are co-localized with cyclo-oxygenase 2 (COX-2) in pyramidal neurons in Alzheimer disease temporal cortex. J Neuropathol Exp Neurol 2002;61:678-688.

10. Nagy Z, Combrinck M, Budge M, McShane R. Cell cycle kinesis in lymphocytes in the diagnosis of Alzheimer's disease. Neurosci Lett 2002;317: 81-84.

11. Sultana R, Mecocci P, Mangialasche F, Cecchetti R, Baglioni M, Butterfield DA. Increased protein and lipid oxidative damage in mitochondria isolated from lymphocytes from patients with Alzheimer's disease: insights into the role of oxidative stress in Alzheimer's disease and initial investigations into a potential biomarker for this dementing disorder. J Alzheimers Dis 2011;24:77-84.

12. Leuner K, Schulz K, Schutt T, Pantel J, Prvulovic D, Rhein V, et al. Peripheral mitochondrial dysfunction in Alzheimer's disease: focus on lymphocytes. Mol Neurobiol 2012;46:194-204.
13. Behrens MI, Silva M, Salech F, Ponce DP, Merino D, Sinning M, et al. Inverse susceptibility to oxidative death of lymphocytes obtained from Alzheimer's patients and skin cancer survivors: increased apoptosis in Alzheimer's and reduced necrosis in cancer. J Gerontol A Biol Sci Med Sci 2012;67:1036-1040.

14. Urcelay E, Ibarreta D, Parrilla R, Ayuso MS, Martin-Requero A. Enhanced proliferation of lymphoblasts from patients with Alzheimer dementia associated with calmodulin-dependent activation of the nat/ H+ exchanger. Neurobiol Dis 2001;8:289-298.

15. Yoon SC, Kwon YA, Kim H, Kim S, Ahn Jo S, Kim DK. Altered cell viability and proliferation activity of peripheral lymphocytes in patients with Alzheimer's disease. Psychiatry Investig 2010;7:68-71.

16. Erkinjuntti T, Inzitari D, Pantoni L, Wallin A, Scheltens P, Rockwood $\mathrm{K}$, et al. Research criteria for subcortical vascular dementia in clinical trials. J Neural Transm Suppl 2000;59:23-30.

17. Kang Y, Na DL, Hahn S. A validity study on the Korean Mini-Mental Status Examination (K-MMSE) in dementia patients. J Korean Neurol Assoc 1997;15:300-308.

18. Ku HM, Kim JH, Kwon EJ, Kim SH, Lee HS, Ko HJ, et al. A study on the reliability and validity of Seoul-Instrumental Activities of Daily Living (S-IADL). J Korean Neuropsychiatr Assoc 2004;43:189-199.

19. Morris JC. The Clinical Dementia Rating (CDR): current version and scoring rules. Neurology 1993;43:2412-2414.

20. Beck AT, Ward CH, Mendelson M, Mock J, Erbaugh J. An inventory for measuring depression. Arch Gen Psychiatry 1961;4:561-571.

21. Rusk R, Hyerstay BJ, Calsyn DA, Freeman CW. Comparison of the utility of two abbreviated forms of the MMPI for psychiatric screening of the elderly. J Clin Psychol 1979;35:104-107.

22. Arbogast A, Boutet S, Phelouzat MA, Plastre O, Quadri R, Proust JJ. Failure of $\mathrm{T}$ lymphocytes from elderly humans to enter the cell cycle is associated with low Cdk6 activity and impaired phosphorylation of $\mathrm{Rb}$ protein. Cell Immunol 1999;197:46-54.

23. Boonstra J. Progression through the G1-phase of the on-going cell cycle. J Cell Biochem 2003;90:244-252.

24. Sanchez I, Dynlacht BD. New insights into cyclins, CDKs, and cell cycle control. Semin Cell Dev Biol 2005;16:311-321.

25. Coqueret O. Linking cyclins to transcriptional control. Gene 2002;299: 35-55.

26. Giovanni A, Wirtz-Brugger F, Keramaris E, Slack R, Park DS. Involvement of cell cycle elements, cyclin-dependent kinases, $\mathrm{pRb}$, and E2F x DP, in B-amyloid-induced neuronal death. J Biol Chem 1999;274: 19011-19016.

27. Arellano M, Moreno S. Regulation of $\mathrm{CDK} /$ cyclin complexes during the cell cycle. Int J Biochem Cell Biol 1997;29:559-573.

28. Morgan DO. Principles of CDK regulation. Nature 1995;374:131-134.

29. Felten DL, Felten SY, Bellinger DL, Carlson SL, Ackerman KD, Madden KS, et al. Noradrenergic sympathetic neural interactions with the immune system: structure and function. Immunol Rev 1987;100:225-260.

30. Gladkevich A, Kauffman HF, Korf J. Lymphocytes as a neural probe: potential for studying psychiatric disorders. Prog Neuropsychopharmacol Biol Psychiatry 2004;28:559-576.

31. Kadioglu E, Sardas S, Aslan S, Isik E, Esat Karakaya A. Detection of oxidative DNA damage in lymphocytes of patients with Alzheimer's disease. Biomarkers 2004;9:203-209.

32. Mecocci P, Polidori MC, Ingegni T, Cherubini A, Chionne F, Cecchetti $\mathrm{R}$, et al. Oxidative damage to DNA in lymphocytes from $\mathrm{AD}$ patients. Neurology 1998;51:1014-1017.

33. Sulger J, Dumais-Huber C, Zerfass R, Henn FA, Aldenhoff JB. The calcium response of human $\mathrm{T}$ lymphocytes is decreased in aging but increased in Alzheimer's dementia. Biol Psychiatry 1999;45:737-742.

34. Tacconi S, Perri R, Balestrieri E, Grelli S, Bernardini S, Annichiarico R, et al. Increased caspase activation in peripheral blood mononuclear cells of patients with Alzheimer's disease. Exp Neurol 2004;190:254-262.

35. Velez-Pardo C, Ospina GG, Jimenez del Rio M. Abeta[25-35] peptide and iron promote apoptosis in lymphocytes by an oxidative stress mech- 
anism: involvement of $\mathrm{H} 2 \mathrm{O} 2$, caspase-3, NF-kappaB, p53 and c-Jun. Neurotoxicology 2002;23:351-365.

36. de las Cuevas N, Urcelay E, Hermida OG, Saiz-Diaz RA, Bermejo F, Ayuso MS, et al. Ca2+/calmodulin-dependent modulation of cell cycle elements $\mathrm{pRb}$ and $\mathrm{p} 27 \mathrm{kipl}$ involved in the enhanced proliferation of lymphoblasts from patients with Alzheimer dementia. Neurobiol Dis 2003; 13:254-263.

37. Munoz U, Bartolome F, Bermejo F, Martin-Requero A. Enhanced proteasome-dependent degradation of the CDK inhibitor p27(kip1) in immortalized lymphocytes from Alzheimer's dementia patients. Neurobiol Aging 2008;29:1474-1484.

38. Zana M, Juhasz A, Rimanoczy A, Bjelik A, Baltas E, Ocsovszki I, et al.
Alzheimer's lymphocytes are resistant to ultraviolet B-induced apoptosis. Neurobiol Aging 2006;27:831-834.

39. Husseman JW, Nochlin D, Vincent I. Mitotic activation: a convergent mechanism for a cohort of neurodegenerative diseases. Neurobiol Aging 2000;21:815-828.

40. Timsit S, Rivera S, Ouaghi P, Guischard F, Tremblay E, Ben-Ari Y, et al. Increased cyclin D1 in vulnerable neurons in the hippocampus after ischaemia and epilepsy: a modulator of in vivo programmed cell death? Eur J Neurosci 1999;11:263-278.

41. van Lookeren Campagne M, Gill R. Increased expression of cyclin G1 and p21WAF1/CIP1 in neurons following transient forebrain ischemia: comparison with early DNA damage. J Neurosci Res 1998;53:279-296. 